\title{
Correction to: Energy-efficient routing in the proximity of a complicated hole in wireless sensor networks
}

\author{
Khanh-Van Nguyen ${ }^{1} \cdot$ Chi-Hieu Nguyen ${ }^{1} \cdot$ Phi Le Nguyen $^{1} \cdot$ Tien Van Do $^{2} \cdot$ Imrich Chlamtac $^{3}$
}

Published online: 16 April 2021

(C) The Author(s) 2021

\section{Correction to:}

\section{Wireless Networks} https://doi.org/10.1007/s11276-021-02569-3

During the typesetting process, an incorrect version of Figure 7 has been introduced in a paper entitled "Energyefficient routing in the proximity of a complicated hole in wireless sensor networks" published in Wireless Networks. The correct version of Fig. 7 is shown below.
The original article can be found online at https:// doi.org/10.1007/s11276-021-02569-3.

\section{Phi Le Nguyen}

lenp@soict.hust.edu.vn

Khanh-Van Nguyen

vannk@soict.hust.edu.vn

Chi-Hieu Nguyen

20151331@student.hust.edu.vn

Tien Van Do

do@hit.bme.hu

1 Hanoi University of Science and Technology, Hanoi, Vietnam

2 Department of Networked Systems and Services, Budapest University of Technology and Economics, Budapest, Hungary

3 University of Trento, Trento, Italy

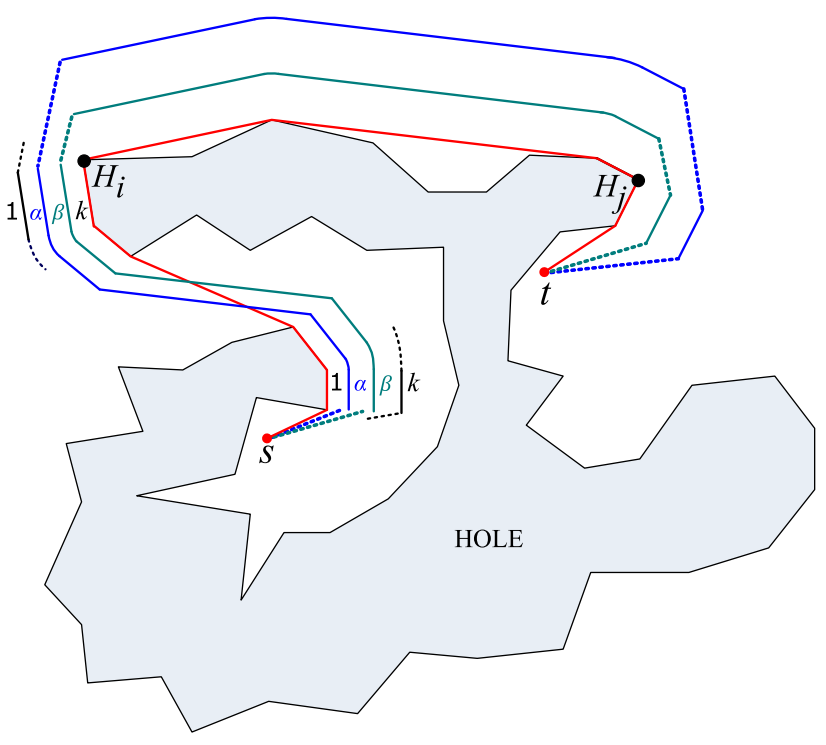

Fig. 7 Paths in the network: The red path is the shortest path, the green path and the blue path represent two Euclidean routing paths of two packets from $s$ to $t$

The original article has been corrected.

Publisher's Note Springer Nature remains neutral with regard to jurisdictional claims in published maps and institutional affiliations. 